Article

\title{
Resistance and Representation in a Wildland-Urban Interface Fuels Treatment Conflict: The Case of the Forsythe II Project in the Arapaho-Roosevelt National Forest
}

\author{
Hannah Brenkert-Smith ${ }^{1, *}$, Jody L. S. Jahn ${ }^{2}$, Eric A. Vance ${ }^{3}\left(\mathbb{D}\right.$ and Juan Ahumada ${ }^{2}$ \\ 1 Environment and Society Program, Institute of Behavioral Science - UCB 483, University of Colorado, \\ Boulder, CO 80309, USA \\ 2 Department of Communication, University of Colorado Boulder, Boulder, CO 80309, USA; \\ jody.jahn@colorado.edu (J.L.S.J.); Juan.Ahumada@colorado.edu (J.A.) \\ 3 Department of Applied Mathematics, Engineering Center, Boulder, CO 80309, USA; eric.vance@colorado.edu \\ * Correspondence: hannahb@Colorado.EDU
}

Received: 23 November 2019; Accepted: 21 December 2019; Published: 24 December 2019

check for updates

\begin{abstract}
Land treatments in wildland-urban interface (WUI) areas are highly visible and subject to public scrutiny and possible opposition. This study examines a contested vegetation treatment-Forsythe II-in a WUI area of the Arapaho-Roosevelt National Forest in Colorado. An initial phase of the research found vocal opposition to Forsythe II. The purpose of the present study was to understand how well the resistance narrative represented the broader community in the WUI area affected by the Forsythe II treatments. More than one third (36\%) of households responded to a census survey focused on Forsythe II, demographics, wildfire risk perceptions, and variables associated with generic land management activities and place attachment. Overall, while public opposition to Forsythe II has resulted in a nearly $25 \%$ reduction in the project's size, the survey data demonstrate that just over a quarter of respondents $(27 \%)$ opposed or strongly opposed the Forsythe II project, and the majority of survey respondents reported broad support for forest management approaches similar to those detailed in the project plans. Notably, a similar portion $(28 \%)$ did not report an opinion on the project. Results include a systematic comparison of opinion/no opinion respondents.
\end{abstract}

Keywords: fuels treatment; social science; conflict; systematic data collection; forest management; attitudes and beliefs

\section{Introduction}

Managing wildfire risk at the wildland-urban interface (WUI) entails a complex set of social and biophysical challenges, shaped in part by the intermixing of residences within and adjacent to public lands. The mosaic of landownership is a significant concern for fire, fuels, and other land managers due in part to forest conditions that put lives and properties at risk of wildfire-related damage and loss. Land and fuel treatments in WUI areas that are intended to meet goals that include risk reduction and forest resilience are particularly visible to those who inhabit the private lands adjacent to public lands. Further, those who inhabit private lands in WUI areas stand to both benefit from risk reduction and endure changes in forest conditions that are required to generate resilient landscapes [1]. This visibility and proximity expose fuel reduction efforts to public scrutiny, and sometimes opposition [2,3]. Social science research on the public acceptability of fuel management on public lands demonstrates broad public support [4-7]. Most studies, however, report on general 
measures of support, rather than efforts to measure responses to specific fuel treatments. However, the successful implementation of land and fuel management activities to reduce wildfire risk may face opposition, litigation, significant modification, or even be abandoned if agencies and their stakeholders cannot find common understandings of the current or desired conditions of the lands that are subject to management [8-10]. Understanding local sentiments toward specific fuel treatments for actual places, however, is generally relegated to public processes land managers undertake during the phases in which project feasibility is assessed. The need to understand potential patterns in the public acceptance of and potential obstacles to the implementation of actual fuels treatment projects is imperative, particularly in light of recent wildfire disasters in WUI areas. Both fire science and recent major fires demonstrate that landscape-scale fuels, fuels directly adjacent to a home [11,12], as well as structures (homes and other buildings) [13,14] and their arrangement [15] all constitute key contributors to WUI disasters, making fuel management at the intersection of wildland and urban fuels particularly critical. More so, the population at risk is projected to increase, particularly in the American West, due to the vast and still undeveloped WUI $[16,17]$. This expansion potential necessitates continued investment in building more nuanced understandings of potential barriers to keeping communities safe through infrastructure, fuel, and forest management.

The work presented here is the result of a two-phase research endeavor in which the focus of the study evolved through the course of the work. Initially, we sought to understand public perspectives in relation to a specific fuel treatment project, Forsythe II, that has been the subject of a great deal of attention due to a vocal and organized opposition (hereafter: Opposition Group) that rejected and sought to resist multiple aspects of the project. In the first phase of the study, we used qualitative methods to gain insight into how residents in the areas most directly affected by the proposed fuels treatments characterize resilient landscapes and their perspectives on the work planned for Forsythe II. Findings from this effort suggested that participants who supported the fuel reduction plans carried broad goals for the landscape, including forest resilience and community safety. Their characterization of the work appeared to align with the stated intentions of the U.S. Forest Service (USFS). In contrast, the Opposition Group entailed a vocal and passionate resistance to the project, anchored in a perspective that maintained that fuel treatments would entail the degradation and loss of a beloved landscape, and was shrouded by violated expectations by federal land managers and prior land manager mistakes $[18,19]$.

However, the extent to which the views captured represented the views of the broader population remained unclear from the first phase of research. As such, the findings presented here are the result of the second phase of the study, which sought to measure the attitudes and beliefs of the broader population in the Forsythe II project area. We wanted to determine to what extent the Opposition Group's perspective represent the views of the broader population, and whether the vocal opposition to the proposed fuel reduction project constitutes a position that garners an outsized response. In the following sections, we consider the relevant literature that informed the construction of the survey instrument and describe the study context. In the results section, we present descriptive results for the variables included in a stepwise regression analysis as well as the results of that analysis.

\section{The Potential for Conflict when Managing Meaningful WUI Landscapes}

A core component of natural resource management entails the social dimensions of management $[20,21]$. The literature on forest management, place attachment, and wildfire suggest that several key factors may influence public acceptance or opposition to landscape change. We briefly engage with this literature below.

Research related to forest and fuel management has generally demonstrated public support for the management of public lands [5,7,22], consistently documenting the role of trust in land managers in acceptability of fuel or forest management practices [7,23-26]. Importantly, Winter, Vogt, and McCaffrey [24] found that believing that land managers are competent is a critical component of that trust. Likewise, Vaske et al. [7] surveyed residents in rural Colorado and found that respondents 
generally shared values with USFS managers and expressed trust in agency personnel to use mechanical thinning and prescribed burning effectively. Social trust was determined to mediate the relationship between value similarity and attitudes toward measured fuel management techniques. Trust in the ability to implement fuel treatment, however, may be vulnerable to missteps, including escaped prescribed fires [27]. One longitudinal study that examined perspectives in 1996 and again in 2000 found overall ongoing public support for fuel and fire management that included mechanized thinning and prescribed fire in Oregon and Washington, but found that between the two study periods, respondents found information programs from the USFS as less useful and reported significantly lower levels of trust in the USFS [23]. Further, respondents in this study were less likely to agree that the USFS makes plans with the input from local communities or uses public input to shape management decisions [23]. Importantly, research has demonstrated geographic variation in acceptability, and that the method of implementation matters (e.g., mechanical, selective thinning, or prescribed fire) $[5,22,26]$. In other words, despite general findings of support, the research indicates that trust is critical, and the techniques and locations of the fuel treatments matter. Further, beliefs about the outcomes of such projects, including air quality, the likelihood of escaped prescribed fire, and aesthetic impacts, are important to nearby residents [26]. Indeed, the aesthetics of a landscape are an important consideration and shape people's views of a proposed treatment.

The place attachment literature has clearly established the importance of emotional relationships, which can "encompass a broad range of physical settings and emotions". Indeed, "relationships to places are an ever-changing, dynamic phenomenon, and as such, they can be a conscious process in which people are active shapers of their lives" [28]. Since places are not simply physical, but are physical spaces imbued with meanings, activities, things, and understandings [29], people's relationships to place are both deeply personal and emotional, and simultaneously "exist within a larger socio-political milieu" [28]. The scope of places can range from the small and immediately controllable-such as a favorite armchair-can encompass places within which social interactions occur-such as your neighborhood or city —or might expand as far as the state, nation, or the planet [29]. The natural environment is also imbued with social and cultural meaning and is subsequently viewed from cultural definitions [30]. The frames, or interpretive schemes, used to describe environmental issues may reflect the values, worldviews, or institutional affiliation of the decision maker [31]. Frames provide coherent explanations, and those that differ may result in conflict [31-33].

It stands to reason that there may be a gap between general public support for the concept of fuel management for forest resilience and/or public safety and public views on the details of a specific fuel reduction project intended for a beloved landscape. Once a forest management project is planned for a specific place, one's sense of place can serve as a filter by which such management activities may be evaluated. As a project transitions from concept to proposal, how one makes sense of the proposed actions and judges the appropriateness may be subject to a different set of evaluative criteria. Certainly, theorizing on sensemaking suggests that conflicts can arise because it is the logics that one constructs through experience, interaction, and emotion that not only provide the framing of the problem, but also the potential solutions for resolution [34,35].

Moreover, the process by which people make sense of a place and how it may change under proposed treatment plans may be tied to place identity, or one's sense of self. Overall, this literature emphasizes that even personal identity is enacted daily through meaningful places, indicating that how people interpret environmental issues may be particularly personal [36], especially if people interpret change as a threat. In other words, a place is imbued with meaning, in part through the stories one tells about one's self in that place [28,37]; stories of how that place may change are no less important. Further, place dependence suggests that some experiences are uniquely tied to a specific landscape for which substitutes may not exist [38]. If a sense of self may actually be so intertwined as to be dependent on a place, proposed changes to that place may be particularly personal and the fodder for conflict. 
A central issue for implementing management prescriptions in the wildland-urban interface is that WUIs are comprised of a range of communities that may hold different perspectives on both the place they collectively occupy and the entities (agencies, in this case) charged with management responsibilities [39-41]. Indeed, stakeholders may have conflicting perspectives on how best to manage private and public interests to protect residents and the communities they occupy from destructive wildfires, particularly at the intersection of private and public lands $[3,39,40]$. Furthermore, the research also indicates that while variation in attitudes and beliefs about wildfire might vary somewhat at the community level, they are more likely to vary at the individual level [9]; this finding highlights the potential for within community diversity and conflict [41]. Phase 1 of this project (discussed next) explored one such case of within-community opposition to a vegetation treatment, setting the foundation for the present study.

\section{Forsythe II: Case Description and Project Background}

The Forsythe II project, designed for the Arapaho-Roosevelt National Forest lands surrounding the town of Nederland, Colorado, is a fuel management effort intended to meet a number of goals. Project documents indicate that the primary goals are to "reduce the buildup of forest fuels that increase the severity of wildfire and to help improve the condition of forest stands to make the area more resilient to future natural disturbances such as drought, disease, and insects." The project area is of particular concern due to increased wildfire activity, growth of the proximate WUI, and recent wildland fires that have resulted in homes being burned. The project includes a combination of thinning in mixed conifer areas, clear-cuts in Lodgepole pine stands, and prescribed burning [42]. The project "also provides an opportunity to create defensible space on National Forest lands that border their private land" (Figure 1) [43]. The final project plan entails fuel reduction on 2460 acres over the next 5-10 years and is the product of an extended public process, which included a conflict resolution process [44]. A summary of changes from USFS includes a reduction in acres subject to proposed treatment by more than a thousand acres, "reducing the area, amount, and size of trees to be treated within all vegetation types", and the creation of 300-foot no-cut buffer along the boundary of all private lands $[45,46]$. Implementation of a multi-party monitoring group, led and facilitated by the Colorado Forest Restoration Institute at Colorado State University, was also added to the plan in order to meet community concerns.

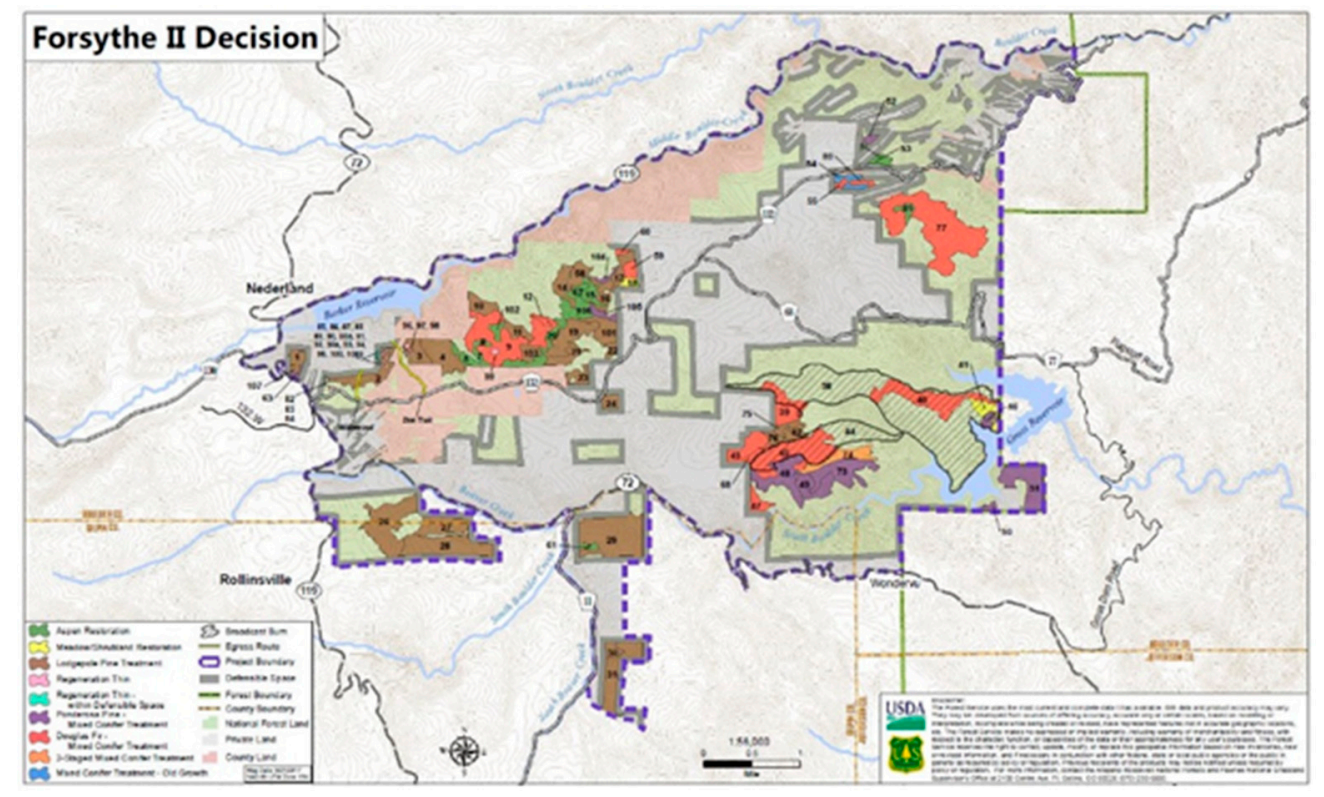

Figure 1. Forsythe II Decision. 
Previous research in the area had suggested that formal stakeholders (e.g., USFS, county fire and forest program leads) in the western Boulder County area shared a high level of alignment in their characterization of the challenges of and appropriate pathways to support healthy and resilient forests [47]. That work, however, focused on formal stakeholders and did not engage the public. Further, as with most of the research on the public acceptability of fuel management, it explored forest and fuel management broadly, rather than with a focus on any specific past or planned fuel treatment effort. The project described here builds on and extends the findings from a previous project carried out in 2014-2015, led by Toman and colleagues [47]. Public outcry surrounding the fuels treatments planned for Forsythe II suggested an opportunity to explore public engagement surrounding a specific fuels treatment. The study described here directly extends previous efforts by focusing on a specific project approved for implementation.

The first, qualitative phase of the present research project sought to explore the community characterization of the surrounding public lands, notions of forest resilience, and understandings of the intent and perceived appropriateness of the Forsythe II project [18,19]. During this phase of the research, we gathered data using participant observation (11 public meetings over two years), focus groups (31 focus group participants) and in-depth interviews (11 individuals). The research team documented how people made sense of the landscape through the generation of explanations for a set of circumstances-a process called sensemaking, referring to how people generate understandings of circumstances or events through creating plausible accounts for situation they have faced [48].

The data from the first phase of research indicated that in the Forsythe II case, study participants demonstrated that they made sense of the planned fuel treatments by integrating notions of space and place into the framing of how changes from the proposed treatments might alter the surrounding landscapes. These frames were embedded with specific spatial references and reflected retrospective and prospective views about the landscape, highlighting what it was and what it could be. Specifically, conflicting frames were characterized as either retrospective or prospective in relation to anticipated changes to the landscape resulting from fuel treatments and wildfire. However, the conclusions from the first phase of research do not focus on within community conflict, but rather on the conflict between a group of residents organized against the Forsythe II project and the USFS. Importantly, the data indicated that both prospective and retrospective frames were tightly bound to place attachment, attitudes about forest management, and understandings of wildfire. The heart of the Opposition Group's retrospective narrative included what they felt were their violated expectations and land managers' prior mistakes in management practices, and the perceived potential for degradation and loss of a loved landscape. In contrast, the prospective frame of supportive residents looked forward to the benefits of fuel treatment, which included the promise of improved forest resilience and community safety $[18,19]$. In other words, beliefs about how deeply valued landscapes would change as a result of fuel treatments played an outsized role in shaping interpretations of the appropriateness of the Forsythe II project.

The nature of the qualitative findings reflects the ways in which such research allows a deep dive into the interpretation of how study participants make sense of their world: how they understand, characterize, or frame a problem [49]. This kind of deep dive often reveals nuance and provides a better understanding of social processes, particularly those involving conflict. The limitations to this approach, however, include the fact that qualitative research does not allow the researchers to discern the extent to which the nuanced understandings they have uncovered represent the broader population $[49,50]$.

Despite having collected rich data providing insights into the ongoing conflict and the extent to which the Forsythe II process had entailed compromises to meet local objections, interactions with representatives of the USFS suggested that there was more to the story [18]. USFS representatives repeatedly asserted that they had public support to move forward, even with the original plan, and it became critical to explore the extent to which views of the Opposition Group represented the broader Nederland community population and other residents living nearest to the slated treatment sites. 
Therefore, we explore whether the conflicts that appeared to be intractable through the narratives of the Opposition Group represented the broader community or whether the conflict represented a small segment of the population engaged in an outsized resistance. In other words, to what extent do the narratives of resistance from the Opposition Group documented in Phase 1 of the project represent the broader community in the Forsythe II project area?

\section{Methods}

\subsection{Survey Plan and Data Collection}

We built a survey administration plan that invited one participant from every household in the zip code area for the Nederland community (80466) [51] in order to engage the emergent research question: To what extent do the narratives of resistance from the Opposition Group documented in Phase 1 of the project represent the broader community in the Forsythe II project area? We used a census approach to eliminate sampling error and to ensure we provided the broadest opportunity for residents to respond with their views on the project. The research team crafted a survey instrument based on the research literature discussed above, data from the qualitative portions of the study, and input from local leaders. The survey instrument was accompanied by a cover letter providing background on the study, which was co-signed by representatives from a range of organizations in hopes of ensuring broad public participation. Co-signers included the project manager of Boulder County Wildfire Partners, the Chief of the Nederland Fire Department, the Mayor of the Town of Nederland, and the leader of the most vocal local opposition group, the Opposition Group.

Data collection was initiated at the end of September 2017 (see details in Table 1). First, letters of invitation were mailed on 24 September 2017 with a two-dollar token of appreciation to 2171 households. This letter introduced the study and invited residents to participate in the survey online, which resulted in a number of early responses (134) and allowed us to cull the mailing list of bad addresses (274). Second, on 19 October 2017, another mailing was sent to 1763 residents. This time, the packet included a slightly modified cover letter with the same signatories, a paper survey, and a postage-paid return envelope. Third, a second survey packet with a slightly modified cover letter with the same signatories was mailed on 9 November 2017 to those who had yet to respond (1576). Fourth, a final mailing was conducted on 21 November 2017, for which half the remaining non-respondents were mailed a letter with the weblink (685) and the other half of the non-respondents were mailed a letter with a weblink, along with a paper survey and return envelope (685).

Table 1. Mailing strategy to every household within 80466 zip code.

\begin{tabular}{ccc}
\hline & Dates & Numbers Mailed \\
\hline Initial letter-web link + \$2 incentive & 24 September 2017 & 2171 (1897 delivered) \\
Packet 1—survey packet \& web link & 19 October 2017 & 1763 \\
Packet 2—survey packet \& web link & 9 November 2017 & 1576 \\
Final mailing A-web link & 21 November 2017 & 685 \\
Final mailing B-survey packet \& web link & 21 November 2017 & 685 \\
\hline
\end{tabular}

We received 637 survey responses representing a 36\% response rate. Well over half $(63.11 \%)$ of the responses were completed via the web-based survey, while $36.89 \%$ completed the survey with a traditional mail-in paper survey. Responses that contained more than $50 \%$ blank answers were omitted from the data set during cleaning $(n=10)$. For other item blank answers, responses were imputed using the average response for that data set on that item for the purposes of the stepwise regression analysis. After cleaning the data set, we were left with a data set of 627 responses. 


\subsection{Analyses}

First, we present descriptive results in order to provide a broad view of the 627 survey responses, with a focus on the key dependent variable: the extent to which study participants reported support or opposition to the Forsythe II project. Given the high portion of respondents who did not report an opinion on the Forsythe II project, we conducted a systematic comparison to see if the group who had an opinion on the project differed from the group who did not have an opinion. We conducted two-sample $t$ tests for each variable comparing the average of the no opinion group with the average of the opinion group. A two-sample $t$ test is appropriate in this context because the Central Limit Theorem implies that the averages of each group $(n 1=453$ and $n 2=174)$ are approximately normally distributed. Next, we present the results of a stepwise regression that identifies the key variables associated with opinions on the Forsythe II project. Using R v. 3.5.2 [52] we fit a multiple linear regression to predict the level of support for Forsythe II and used forward and backward stepwise regression to arrive at our final model, as shown in Section 5.

\section{Results}

Here, we report on the main findings relevant to the regression analyses presented below. For the variables present, we report the mean and standard deviation range and mean for variables in tables of Sections 5.2-5.6. Variables in bold text in Tables 2-6 comprise the final regression model. We also report the portion responding to the top two Likert categories (e.g., agree/strongly agree) in order to facilitate ease of reporting. As relevant, we also report the portion of item non-response, as this becomes an important part of the findings regarding attitudes toward the Forsythe II project. Full survey results and the survey instrument are available in [19].

\subsection{Who Responded to the Survey?}

The vast majority of respondents (94\%) were full-time residents, occupying their home 12 months of the year, and $88 \%$ own their own home. Almost a third (32\%) of respondents were long-term residents, having moved to their current residence before 1998 ( mean $=15$ years; median $=13$ years). Importantly, almost a quarter (24\%) arrived between 2013-2017, while the remaining $45 \%$ were spread relatively evenly across the years between 1998 and 2012 (see Table 2 for summary statistics). When comparing respondents who had an opinion to those who had no opinion on the Forsythe II project, we see the only personal characteristic that differed was length of tenure. The average length of tenure of those with no opinion was 13 years, while it was nearly 3 years longer (16 years) for those with an opinion on the project.

Table 2. Personal characteristics of survey respondents.

\begin{tabular}{|c|c|c|c|c|}
\hline Variable & Survey Item & Range & Mean (SD) & Value \\
\hline Tenure & In what year did you move into your current residence? (2017-X) & $0-69$ & $15.0(\mathrm{SD} 12.0)$ & -2.50 \\
\hline Income * & $\begin{array}{c}\text { Reported household income }(1=\text { Less than } \$ 9,999 ; 2=\$ 10,000-\$ \\
14,999 ; 3=\$ 15,000-\$ 29,999 ; 4=\$ 30,000-\$ 44,999 ; 5= \\
\$ 45,000-\$ 59,999 ; 6=\$ 60,000-\$ 74,999 ; 7=\$ 75,000-89,999 ; 8=\$ \\
90,000-\$ 104,999 ; 9=\$ 105,000-\$ 119,999 ; 10=\$ 120,000 \text { or more })\end{array}$ & $1-10$ & $\begin{array}{l}7.14(\mathrm{SD} \\
0.107)\end{array}$ & \\
\hline Education & $\begin{array}{l}\text { Less than High school = } 1 \text {; High school or GED = 2; Some college } \\
\text { or tech school/assoc. degree = 3; College grad = 4; Post grad = }\end{array}$ & $2-5$ & 4.1 (SD 0.84) & 0.53 \\
\hline Age & How old are you? & $18-82$ & 55 (SD 13.2) & -0.98 \\
\hline Gender & What is your gender? $(1=$ Female; $0=$ Male $)$ & $0 / 1$ & 0.46 (SD 0.02) & -1.2 \\
\hline
\end{tabular}

Just under half the survey respondents were female (46\%) and most were highly educated, with $20 \%$ reporting having had some college or technical school training, 39\% reporting being a college graduate and another $38 \%$ reporting having had some postgraduate training. Over half $(53 \%)$ of respondents were employed full time and $12 \%$ were employed part-time. Almost a third 
(31\%) were not currently employed and not looking, which we assumed comprised a combination of retirees and homemakers. Finally, survey respondents reported a relatively high level of income, with approximately $49 \%$ reporting a household income of $\$ 90,000$ or more; however, nearly $10 \%$ of respondents reported a household income of less than $\$ 30,000$.

\subsection{What is the Extent of Support or Opposition to Forsythe II?}

We asked the question, "as of today, how strongly do you support or oppose the Forsythe II fuels treatment project proposed by the USFS?", which answers given as a five-point scale. The portion of respondents who reported supporting or strongly supporting (31\%) the Forsythe II project was similar to the portion that indicated that they opposed or strongly opposed $(27 \%)$ the project. Fourteen percent of respondents selected the middle category of the Likert scale. Notably, $28 \%$ of respondents selected "don't know" or "not sure" in response to the question (Figure 2).

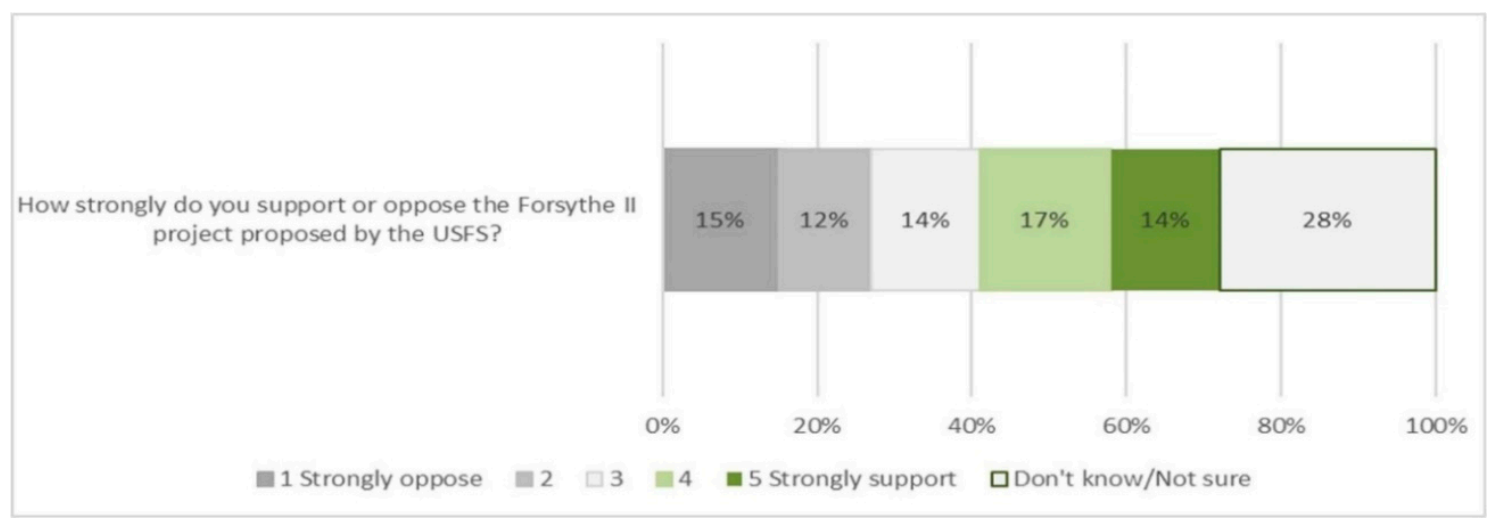

Figure 2. Forsythe II support among survey respondents.

As the project was first proposed in 2014 and has since undergone modifications in response to a number of public processes, it would be reasonable to expect that attitudes today may be different from previous junctures. As such, we asked a short battery of questions about opinion change, whether they believed USFS was responsive to community input, and respondents' participation in these processes. Overall, we saw relatively neutral views overall. Thirty-seven percent of respondents indicated they had a more favorable opinion on the Forsythe II project; however, the mean response was neutral (3.07). Relatively few respondents $(11 \%)$ reported often or always participating in public forums to express views on the project. Notably, however, a large portion of respondents opted to select "don't know", "not sure" or "not applicable" responses in this battery. Twenty-eight percent of respondents selected this option in response to the key question: the extent of their support or opposition to the Forsythe II project. Likewise, $67 \%$ indicated that they did not know or were not sure whether or not the USFS had made changes in response to community members' input (See Table 3 for summary statistics).

It is fair to suspect that not all respondents were aware of the processes through which the original Forsythe II project had been amended. As such, we sought to gain insight into whether or not respondents thought that the USFS had made changes in response to community members' input. The majority of respondents indicated they did not know (67\%), while a small portion of respondents $(16 \%)$ reported that they thought the USFS rarely or never made changes to project plans based on community members' input. Likewise, $16 \%$ reported that such changes occurred often or sometimes. We were also interested in knowing what portion of our study respondents had participated in any of the available opportunities to provide feedback to the USFS regarding Forsythe II. We asked how often respondents had participated in any process, providing examples such as "provided public comment during public comment period; attended tours, meetings, or open houses hosted by the USFS, etc.". Well over a third $(37 \%)$ reported never having participated, and nearly a fifth $(17 \%)$ reported having rarely participated. Another fifth (18\%) of respondents reported that the question was not applicable 
to them. In other words, over $75 \%$ of survey respondents had either never or rarely participated in any type of public forum in which they had an opportunity to voice their opinion, or they considered such forums not to be applicable. The t-tests conducted to systematically assess potential differences between the opinion group and the no opinion group indicate that the mean response of the two groups varied on the small battery of questions about USFS's management of Forsythe II. First, we see that the mean response of the no opinion group indicated that their opinions had become slightly more favorable (3.4) since the time that they first heard about the project. In contrast, the mean response for the opinion group (3) indicated no reported change in opinion since they first heard about the Forsythe II project.

Table 3. Views on U.S. Forest Service (USFS) management of Forsythe II.

\begin{tabular}{|c|c|c|c|c|c|}
\hline Variable & Survey Item & Mean (SD) & PRTTLC & $\begin{array}{l}\text { PR DK/Not } \\
\text { Sure/NA }\end{array}$ & $t$-Test \\
\hline Forsythe_II (DV) & $\begin{array}{l}\text { As of today, how strongly do you support or oppose the } \\
\text { Forsythe II fuels treatment project proposal? ( } 1 \text { = Strongly } \\
\text { oppose; } 5 \text { = Strongly support) }\end{array}$ & $3.04(0.07)$ & $31 \%$ & $28 \%$ & \\
\hline Opinion_change & $\begin{array}{l}\text { How have your opinions changed regarding the Forsythe } \\
\text { II project since the first time you heard about it? }(1=\mathrm{A} \text { lot } \\
\text { less favorable; } 5=\mathrm{A} \text { lot more favorable) }\end{array}$ & $3.07(1.2)$ & $37 \%$ & & $5.8^{* * *}$ \\
\hline USFS_inputchange & $\begin{array}{l}\text { How often has the USFS made changes to the Forsythe II } \\
\text { plan in response to community members' input? }(1= \\
\text { Never; } 5 \text { = Always) }\end{array}$ & $2.58(0.88)$ & $14 \%$ & $67 \%$ & $-14.4^{* * *}$ \\
\hline USFS_compromise & $\begin{array}{l}\text { To the best of your knowledge, how often has the US } \\
\text { Forest Service (USFS) been willing to compromise }(1= \\
\text { Never; } 5 \text { = Always) }\end{array}$ & $2.90(1.6)$ & $35 \%$ & $14 \%$ & $5.7^{* * *}$ \\
\hline Participation & $\begin{array}{l}\text { How often have you participated in public forums to } \\
\text { express your views about Forsythe II? (1= Never; } \\
5=\text { Always) }\end{array}$ & $1.98(1.1)$ & $11 \%$ & $18 \%$ & $-12.9^{* * *}$ \\
\hline
\end{tabular}

Overall, participation in events related to Forsythe II was very low across the study respondents. The mean response for those in the no opinion group (1.2) was lower compared to the mean for the opinion group (2.0). When asked whether they thought the USFS has been willing to compromise, those in the no opinion group had a slightly higher average response (2.9) compared to the mean of those with an opinion (2.2). Finally, when asked about the extent to which the USFS had made any changes to the Forsythe II project based on community input, only $4 \%$ of those in the no opinion group responded to this question. In contrast, $44 \%$ of those with an opinion on Forsythe II project weighted in with an opinion about compromises made by USFS in response to community input.

\subsection{A Meaningful Landscape (i.e., Place Attachment)}

At the outset of the research study, we sought to better understand how residents understood and characterized their relationships to the landscape. Not surprisingly, the vast majority of respondents reported strong attachments. Eighty-five percent of respondents agreed or strongly agreed with the statement "I feel the public land surrounding Nederland is a part of me". Likewise, $86 \%$ of respondents agreed or strongly agreed with the statement "When I spend time in the public lands surrounding Nederland, I feel a deep sense of one-ness with the natural environment". Along with this strong personal connection to the landscape, residing in close proximity allowed for engaging in desirable activities. As such, $81 \%$ reported that they agreed or strongly agreed that the public land surrounding Nederland "is the best place for what I like to do". Importantly, this connection to the landscape may be related to further characterization of local public lands that was echoed repeatedly in the qualitative study (focus groups and interviews); this sentiment was reflected in the $87 \%$ of respondents who agreed or strongly agreed that they considered "the public lands surrounding Nederland to be a part of my 'backyard'” (See Table 4 for summary statistics). 
Table 4. Place attachment variables.

\begin{tabular}{|c|c|c|c|c|}
\hline Variable & Survey item & Mean (SD) & PRTTLC & t-Value \\
\hline \multicolumn{5}{|c|}{ Place variables: To what extent do you agree or disagree with the following statements $(1=$ Strongly Disagree; $5=$ Strongly Agree $)$} \\
\hline Place Part of me & $\begin{array}{l}\text { I feel the public land surrounding Nederland is part } \\
\text { of me. }\end{array}$ & $4.31(0.98)$ & $85 \%$ & 1.8 \\
\hline Place what I like to do & $\begin{array}{l}\text { The public land surrounding Nederland is the best } \\
\text { place for what I like to do. }\end{array}$ & $4.19(0.99)$ & $81 \%$ & 0.79 \\
\hline Place public backyard & $\begin{array}{l}\text { I consider the public lands surrounding Nederland } \\
\text { to be part of my "backyard." }\end{array}$ & $4.39(0.93)$ & $87 \%$ & $2.1 *$ \\
\hline $\begin{array}{l}\text { Place one with } \\
\text { environment }\end{array}$ & $\begin{array}{l}\text { When I spend time in the public lands } \\
\text { surrounding Nederland, I feel a deep sense of } \\
\text { one-ness with the natural environment. }\end{array}$ & $4.36(0.04)$ & $86 \%$ & $2.1 *$ \\
\hline Place friendships & $\begin{array}{l}\text { The friendships developed by doing various } \\
\text { community activities connect me to the public lands } \\
\text { surrounding Nederland. }\end{array}$ & $3.63(1.1)$ & $53 \%$ & $-2.4^{* *}$ \\
\hline \multicolumn{5}{|l|}{ Attachment variables } \\
\hline $\begin{array}{l}\text { Attachment after } \\
\text { wildfire }\end{array}$ & $\begin{array}{l}\text { After a wildfire, my attachment to the public lands } \\
\text { around Nederland would be } \ldots(1=\text { much weaker, } 2 \\
\text { weaker, } 3=\text { same, } 4=\text { stronger, } 5=\text { much stronger })\end{array}$ & $3.37(0.99)$ & $26 \%$ & 1.3 \\
\hline $\begin{array}{l}\text { Attachment after } \\
\text { fuels treatment }\end{array}$ & $\begin{array}{l}\text { After fuels treatment activities on the public lands } \\
\text { around Nederland, my attachment would be } \ldots \\
\qquad(1=\text { much weaker; } 5=\text { much stronger })\end{array}$ & $3.04(1.0)$ & $26 \%$ & 1.7 \\
\hline
\end{tabular}

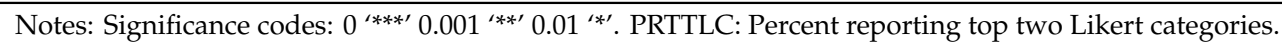

It is notable, however, that despite the fact that many focus group/interview participants reflected on the importance of social ties that are fostered while engaging in activities on public lands (e.g., sharing walks, interacting with community members), only $53 \%$ of respondents agreed or strongly agreed that the "friendships developed by doing various community activities connect me to the public lands surrounding Nederland". The $t$-tests conducted to systematically assess potential differences between the opinion group and the no opinion group indicate that the groups varied on three place variables. The mean value for the no opinion group is significantly higher for the place public backyard (4.5) and place one with environment (4.5) variables than the opinion group (4.3 and 4.3, respectively). In contrast, the no opinion group was significantly lower for the place friendships (3.5) variable than the opinion group (3.7).

\subsection{Retrospective vs. Prospective Framing of Fuel Treatment}

As described previously, interviews from the first phase of the study indicated that the study participants who supported Forsythe II were prospective in their understanding of how both fuel treatments may affect the future forest while those who opposed Forsythe II were retrospective in their framing, describing a forest that may be adversely affected by changes associated with fuel treatments. When asked about how respondents believed their attachment would be affected by fuel treatments, nearly half (49\%) indicated that their attachment would remain the same; however, we saw that $26 \%$ believed their attachment would grow stronger or much stronger, and $(17 \%+8 \%)$ believed that theirs would be weaker or much weaker. Like the other measures, we saw that most respondents did not appear to have a strong feeling about how either fuel treatments or a major fire might alter their attachment to place, and those who did represented a small contingent on either pole.

There was no measurable difference between those in the opinion group compared to those in the no opinion group on these variables (See Table 4).

\subsection{The Wildland-Urban Interface: A Safe Place for Human Habitation and Supporting Healthy Forest Processes}

Despite indications that some respondents anticipated a weakened attachment to a landscape with fuel treatments, there was broad support for fuel treatment activities. Specifically, we asked about a range of types of fuel management activities and asked respondents to indicate the extent to which they believed that the queried activities did the following: how far they (1) "contribute to making the wildland-urban interface (WUI) a safe place for human habitation" and (2) "support what you 
understand to be healthy forest processes". We saw that respondents indicated that they believed that citizens thinning fuels on their properties and having the ability to thin on adjacent public lands, as well as land management agencies thinning, using prescribed burning, and allowing wildfire to burn on public lands, all "supported healthy forest processes". While there was less support for the use of patch cuts to support such processes, over half still supported these practices.

Responses on the extent to which the same practices "made the WUI a safe place for human habitation" varied. Respondents generally reported that citizens thinning fuels on their own properties, having the ability to thin on adjacent public lands, and land management agencies thinning on public lands supported making the WUI safe. While there was less support for land management agencies to engage in patch cuts and prescribed burning, there was still broad support among respondents. The practice that respondents indicated the least support for was land management agencies allowing wildfire to burn on public lands. However, despite lower support, over a third (34\%) supported this practice and another third (32\%) selected a middle, neutral response indicating neither support nor opposition to the practice (see Table 5 for summary statistics).

We see two variables for which there are measurable differences between those in the opinion group compared to those in the no opinion group. The mean response among the no opinion group was slightly higher (4.12) compared to those in the opinion group (3.84) when asked if they believe that land managers thinning on public lands makes the WUI a safe place for human habitation. In contrast, we see a higher mean response for the opinion group (3.02) compared to the no opinion group (2.75) in response to whether land managers allowing wildfires to burn makes the WUI a safe place for human habitation.

Table 5. Forest and fuel management practices: how do the following practices support ... .?

\begin{tabular}{|c|c|c|c|}
\hline Survey Item & Mean (SD) & PRTTLC & $t$-Test \\
\hline \multicolumn{4}{|c|}{ Making WUI a safe place for Human Habitation $(\mathbf{H H})(1=$ Not at all; $5=$ A lot $)$} \\
\hline Citizens thin on own property & $4.24(0.96)$ & $81 \%$ & 1.3 \\
\hline Citizens thin on Federal lands & $3.95(1.1)$ & $70 \%$ & 0.69 \\
\hline Land managers thin on public lands & $3.92(1.2)$ & $70 \%$ & $2.9^{* *}$ \\
\hline Land managers patch cuts & $3.38(1.3)$ & $51 \%$ & 1.6 \\
\hline Land managers prescribed fire & $3.51(1.2)$ & $53 \%$ & 1.5 \\
\hline Land managers allow wildfires to burn & $2.95(1.2)$ & $34 \%$ & $-2.6^{* *}$ \\
\hline \multicolumn{4}{|c|}{ Your understanding of Healthy Forest Processes (HFP) $(1=$ Not at all; $5=$ A lot $)$} \\
\hline Citizens thin on own property & $3.96(1.1)$ & $70 \%$ & -0.97 \\
\hline Citizens thin on Federal lands & $3.73(1.2)$ & $63 \%$ & -0.21 \\
\hline Land managers thin on public lands & $3.73(1.3)$ & $63 \%$ & 1.9 \\
\hline Land managers patch cuts & $3.15(1.4)$ & $45 \%$ & 0.14 \\
\hline Land managers prescribed fire & $3.67(1.2)$ & $60 \%$ & 0.75 \\
\hline Land managers allow wildfires to burn & $3.55(1.2)$ & $57 \%$ & 0.26 \\
\hline
\end{tabular}

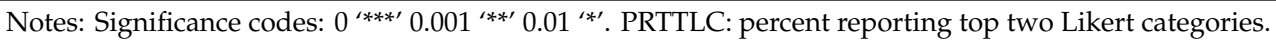

\subsection{Wildfire Specific Beliefs and Behaviors}

We asked respondents to reflect on the extent to which various factors contributed to the chance of wildfire damaging their property in the next five years on a five-point Likert scale from not a contributor (1) to major contributor (5). Overall, the majority $(86 \%)$ of respondents selected the top two categories to characterize the extent to which human activity (e.g., accidental ignition, campfires) contributed to that chance. Sixty-five percent of respondents selected the top two categories to characterize the contribution of weather-related natural starts to the chance of wildfire damaging their property in the next five years. Further, respondents were less likely to select the top two categories when characterizing the contribution of vegetation on public lands (55\%) as a major contributor to a wildfire damaging their property in the next five years, with $55 \%$ reporting that vegetation on public lands was a major contributor, while a similar portion $(52 \%)$ identified vegetation on their neighbors' properties 
as a major contributor. Importantly, when reflecting on the extent to which the conditions of their own property contributed to the risk they faced, only $37 \%$ identified the physical characteristics of their parcels, $41 \%$ identified the physical characteristics of their home or other structures on their property, and only $45 \%$ identified the vegetation on their own property as a notable contributor to the chances of wildfire damaging their property in the next five years (see Table 6 for summary statistics).

Table 6. Wildfire variables.

\begin{tabular}{|c|c|c|c|c|}
\hline Survey Item & Mean (SD) & PRTTLC & $\begin{array}{l}\text { PR DK/Not } \\
\text { Sure/NA }\end{array}$ & $t$-Test \\
\hline \multicolumn{5}{|c|}{$\begin{array}{l}\text { In your opinion, how much does each of the following factors contribute to the chance of a wildfire damaging your property } \mathrm{i} \\
\text { the next five years? ( } 1 \text { = Not a contributor; } 5 \text { Major contributor) }\end{array}$} \\
\hline Vegetation on your property & $3.23(1.4)$ & $45 \%$ & $3 \%$ & 0.37 \\
\hline $\begin{array}{l}\text { Physical characteristics of your property other than vegetation } \\
\text { (e.g., steep inclines) }\end{array}$ & $2.92(1.4)$ & $37 \%$ & $3 \%$ & 0.52 \\
\hline $\begin{array}{l}\text { Physical characteristics of your house or other buildings (e.g., } \\
\text { roofing or siding) }\end{array}$ & $3.09(1.4)$ & $41 \%$ & $3 \%$ & -1.5 \\
\hline Vegetation on your neighbors' properties & $3.43(1.3)$ & $52 \%$ & $3 \%$ & -1.3 \\
\hline $\begin{array}{l}\text { Vegetation on nearby public lands (e.g., National Forest, National } \\
\text { Park, Open Space, greenbelt) }\end{array}$ & $3.56(1.3)$ & $55 \%$ & $3 \%$ & -0.31 \\
\hline Human activity (e.g., accidental ignition, campfires, etc.) & $4.57(0.91)$ & $86 \%$ & $4 \%$ & 0.98 \\
\hline Weather-related natural starts (e.g. lightning) & $3.88(1.0)$ & $65 \%$ & $3 \%$ & -0.77 \\
\hline \multicolumn{5}{|c|}{ If a wildfire reached your property, how likely do you think the following would occur ( $1=$ Not likely at all; $5=$ Very likely) } \\
\hline Firefighters would protect your home & $3.95(1.2)$ & $67 \%$ & $4 \%$ & 0.35 \\
\hline \multicolumn{2}{|c|}{$\begin{array}{l}\text { In the past } 5 \text { years, have you done any of the following to reduce wildfire risk to } \\
\text { your residence? }(1=\text { Yes; No = } 0)\end{array}$} & PRY & & \\
\hline \multicolumn{2}{|l|}{ Reduce the amount of vegetation within 100 feet of your home? } & $87 \%$ & & -1.5 \\
\hline \multicolumn{2}{|c|}{ Reduce the amount of other combustible items within 30 feet of your home } & $89 \%$ & & $-2.56^{*}$ \\
\hline \multicolumn{2}{|l|}{ Changed exterior building materials to something less combustible } & $37 \%$ & & -1.9 \\
\hline \multicolumn{2}{|l|}{ Had your property assessed by Boulder County Wildfire Partners } & $30 \%$ & & -0.14 \\
\hline
\end{tabular}

When asked about actions that respondents had taken to reduce the risk of wildfire to their residence, $87 \%$ had reduced vegetation within 100 feet of their home and $89 \%$ reported having reduced other combustible items from within 30 feet of their home. Notably, fewer (37\%) reported having changed exterior building materials to something less combustible. Thirty percent of respondents reported having had their property assessed by Boulder County Wildfire Partners. Fifty-three percent of respondents reported having taken "other" risk reducing steps, though the survey did not capture the nature of those activities. When asked to consider what might occur if a wildfire reached their property, $67 \%$ reported that it was likely or very likely that a firefighter would protect their home.

The $t$-tests conducted to compare the mean response for the opinion group compared to the no opinion group found that $90 \%$ of those in the opinion group reporting having reduced the amount of other (non-vegetative) combustibles within 30 feet of their home, compared to $82 \%$ of those in the no opinion group.

\subsection{What Factors are Associated with Support or Opposition to Forsythe II?}

We ran a multiple linear regression model with all the variables described in the tables above in order to identify the key variables associated with strength of support/opposition. Among the 627 survey respondents, 453 had an opinion on the central variable. In this regression analysis, we identified six key variables associated with strength of opinion (see Table 7). 
Table 7. Results of stepwise regression for support for the Forsythe II project.

\begin{tabular}{ccc}
\hline & Estimate & Std. Error \\
\hline Intercept & 0.12 & 0.24 \\
Place one with environment & $-0.12^{* *}$ & 0.04 \\
Attachment after fuels treatment & $0.18^{* * *}$ & 0.05 \\
Land Managers Thin for Human Habitation & $0.19^{* * *}$ & 0.05 \\
Land Managers Patch cut for Human Habitation & $0.20^{* *}$ & 0.07 \\
Land Managers Patch cut for Healthy Forest Processes & $0.27^{* * *}$ & 0.06 \\
Land Managers prescribed fire for Healthy Forest Processes & $0.18^{* * *}$ & 0.04 \\
\hline Notes: Adjusted R-squared: 0.599; Significance codes: $0^{* * * * \prime} 0.001^{* * *} 0.01^{* * \prime}$. &
\end{tabular}

First, the more strongly respondents agreed with the statement "When I spend time in the public lands surrounding Nederland, I feel a deep sense of one-ness with the natural environment", the less support they reported for the Forsythe II project. The remainder of the variables operated in the opposite direction. We saw that if respondents reported that they anticipated feeling more attachment to the landscape after a fuel treatment project, they expressed more support for the project. Then, we saw responses to four general forest management practice opinion questions associated with support for the project. In particular, those who agreed that "Land management agencies thinning on public lands to reduce wildfire loss/damage" and "Land management agencies implementing patch cuts on public lands in the appropriate forest type to reduce wildfire loss/damage" supported making the WUI safe for human habitation also indicated stronger support for Forsythe II. Similarly, those who agreed that "Land management agencies implementing patch cuts on public lands in the appropriate forest type to reduce wildfire loss/damage" and "Land management agencies managing public land using prescribed fire" supported healthy forest processes tended to indicate stronger support for Forsythe II. The adjusted R-squared indicated that the regression explains nearly $60 \%$ of the variation on our key question regarding support/opposition toward the Forsythe II project.

In interpreting the results of this regression, one variable was strongly associated with lower support for the Forsythe II project; that is, the more strongly one reported feeling a sense of "one-ness" with nature, the lower their support for the project. This appeared to suggest that stronger place attachments ran counter to support to the project. However, the qualitative findings suggested that, when respondents were directly asked about their attachments to the public lands surrounding Nederland and fuel treatments, they expressed a prospective view such that they were supportive of fuel treatments that altered the landscape [18]. In other words, respondents that anticipated a better landscape after a fuel treatment effort were more supportive of Forsythe II.

Critically, we also saw that support for general forest management practices was associated with support for the Forsythe II project. Stronger agreement that thinning and patch cuts on public lands make the WUI safer for human habitation was associated with stronger support for Forsythe II. Likewise, stronger support for patch cuts and prescribed fire for healthy forest processes was also associated with stronger support for Forsythe II. The direction of these relationships was not altogether surprising - if one supports fuel treatments, one supports the Forsythe II project. More broadly, however, these relationships also suggested that across the respondents who had an opinion about the project, their understanding of Forsythe II was consistent with their understanding of the goals of general fuel and forest management techniques. Those who were generally supportive of forest management practices that change the landscape also supported Forsythe II.

\section{Discussion: Rethinking the Narrative Representation Using Systematic Data Provides a Different Story}

The intent of this study was to evaluate the extent to which the vocal opposition to the USFS's Forsythe II project represented the views of the broader population surrounding the project area. This work was undertaken in light of a broader study that sought to illuminate local understandings of forest resilience in light of controversies surrounding the project. The qualitative portions of the 
broader study helped us gain an initial understanding of the ways in which those who opposed the project formulated and articulated their arguments in opposition. The first phase of the study allowed us to better understand the core dimensions of forest attitudes for residents engaged in the debate over Forsythe II. These arguments have continued, regardless of the concessions made by USFS. Those who opposed Forsythe II were not simply pursuing a contrarian agenda; rather, their framing of the planned work likely reflected differences in understandings of the relationship between humans and the management of natural resources. It is possible that no compromise by the USFS on the details of the project plan could ameliorate these differences $[18,53]$.

The focus of the reporting here on the quantitative survey included data collected from the area most affected by the past treatments and future planned activities, which are critical. They demonstrate several important findings. The contrast between prospective and retrospective understandings of the forest and the potential impacts of forest management that appeared in the qualitative data were clear. There were notable consistencies across the survey respondents. First, study respondents, all of whom were in close proximity to public lands, reported a strong sense of attachment. Indeed, the natural landscapes provided by public lands supported important and meaningful connections to the natural world. Further, respondents indicated broad support for fuel treatments for both the support of healthy forest processes and to reduce wildfire risk within the wildland-urban interface.

However, when we turn to look at the Forsythe II project specifically, the survey data demonstrated that while the voices at the ends of the opposition spectrum have yielded a large amount of attention, they did not appear to represent the majority view. When asked specifically about the Forsythe II project, respondents fell into two roughly similarly sized groupings-those who supported the project $(31 \%)$ and those who opposed it $(27 \%)$, allowing us to clearly situate them as project support or opposition. We see $14 \%$ of respondents selected the middle neutral category on the five-point Likert scale. In other words, we see that the opposition group narrative observed in the qualitative data does not appear to represent the broader community. Rather, those that oppose/strongly oppose appear to make up less than a third of respondents, while those who support/strongly support or hold neutral opinions comprise $45 \%$ of respondents.

In the time since the initial proposals of the project, the USFS held numerous opportunities for public comment and feedback. Our survey suggested that, for the most part, respondents have not engaged in the public processes available to them. Over half $(56 \%)$ have rarely or never participated in such opportunities. Sixty-six percent of respondents indicated they did not know or were not sure whether or not the USFS had made any changes to the project based on community members' input. It is not surprising, then, that after these public activities, $40 \%$ reported that their views of the project remained unchanged. This relative indifference is noteworthy in light of the impassioned narratives documented in the first phase of the study, raising questions about the extent to which the opposition's voice and impact may outsize the extent to which the general population of the area objected to the project. We did see, however, that $38 \%$ reported a more favorable view and $22 \%$ reported a less favorable view. In other words, despite low overall engagement in these public activities, there was evidence that there were changing views among participants, though not all in the same direction.

As discussed throughout the results section, $\mathrm{t}$-tests comparing those who had an opinion to those who has no opinion demonstrated a handful of statistically significant differences. While these tests pick up statistical differences in the mean responses of the two groups, the differences are small enough to consider whether these are meaningful. The differences in the other measures likely indicate slightly different orientations toward the items queried, but it would be difficult to argue that these constitute meaningful differences. In all likelihood, measuring and comparing means obscures the ways in which some respondents sit at polar ends of some measurement scales and were likely the voices best represented through the complementary qualitative research from this project [18].

There are three exceptions to this assertion. First, the mean value for the no opinion group is significantly higher for the place one with environment variable than the opinion group. This is 
noteworthy because of the ways in which place attachment functioned to rally the group that organized to resist the Forsythe II project.

Second, $90 \%$ of opinion holders compared to $82 \%$ of no opinion holders reported having completed one of the basic risk mitigation behaviors that is commonly expected of WUI residents: moving combustible items, such as woodpiles, away from their home. The fire science on the home ignition zone has identified that clearing or moving non-vegetative combustibles from the area surrounding the home is a critical step of reducing the likelihood of home ignition. In a hazardous context in which the likelihood of ignition and the potential consequences of a wildfire are both influenced by such activities, finding a measurable difference in this behavior between the two groups indicates opportunities for further engagement to support the adoption of this simple risk reducing action.

The other exception is tenure. We see an approximately three-year shorter average tenure for the no opinion group compared to the opinion group. While three years does not constitute an exceptionally long difference in time, we speculate that longer tenures provide a longer working memory of previous fuel treatment activities and increased opportunities to engage with land managers. Indeed, the longer one lives in a place may be associated with more familiarity and confidence in one's reported opinion about the project.

Finally, these findings lead us consider opposition and support in light of the $14 \%$ of respondents who selected the middle, neutral category on the five-point Likert scale, when asked their opinion about the Forsythe II project. Given that most respondents indicated general support for fuel treatments activities and the numerous opportunities available to engage in public comment, it would seem fair for a public agency to interpret neutral and non-responses as tacit support for the project. Certainly, the data indicate that the overall public sentiment of the population most directly affected by the planned activities was not opposed to the Forsythe II project. As such, it is clear that, despite the fact that those who opposed the project played a notable role in galvanizing activities, and ultimately in influencing changes to the project plan, these did not represent the broader community views.

\section{Conclusions}

The troubled story of the Forsythe II project is especially important when considering the challenges associated with implementing broad, landscape-level forest management and fuel treatment prescriptions. Research indicates general support for fuel treatments; however, most of the studies are relatively small in scope (sample size and geographic scope). Such studies typically seek to gauge sentiments regarding fuel treatments broadly rather than as they relate to specific, planned or proposed fuel treatments. What stands out in the literature is the finding that the details matter: location, type of treatment, and trust in the managers responsible for planning and implementation all influence support.

As with any study, there remain unanswered questions. The broader policy context could provide additional clues to support the interpretation of this study's data as well as guide future inquiry. The relatively affluent nature of the study context's population might indicate a high adaptive capacity to both invest in risk reduction activities and to help ameliorate damages and losses that could result from a significant wildfire event. Undertaking research that compares cases in which communities have resisted fuels treatment could help uncover the relative role of such contextual factors. Respondents' proximity to the fuel treatments and experiences with recent fire events in the area-specifically the Cold Springs fire (2016) and the Fourmile Canyon Fire (2010) — could also shape perceptions of fuel treatment and forest management. Finally, despite a respectable response rate to the overall study, the large portion of study respondents who do not engage in local community events that have specific outcomes for the surrounding landscapes is noteworthy. Gaps in understanding how public agencies can attend to public concerns if such a large portion of the public does not engage in public processes remain.

In this case, if one were to simply follow the fraught narrative of Forsythe II through the local newspapers or track the continued efforts by the USFS to engage with those who are actively engaged in 
resisting the planned efforts, one might surmise that broad community opposition earned concessions that may be consistent with concerns such as treatment type and location. Moreover, while the narrative of the opposition was compelling, it appears that the concessions were the result of a small but notably effective cohort who garnered an arguably outsized amount of attention from the USFS. As a large public institution, the USFS is obligated to attend to public concerns. The response that the opposition brought about in the form of community meetings, objector resolution processes, monitoring committees, etc. has been substantial. As such, it is notable that such a small contingent was able to move such a large institution to undertake significant concessions.

In summary, the household survey demonstrated two key findings: first, the opposition to the fuel treatments planned for the project constituted less than a third of respondents; second, the majority of respondents was broadly supportive of forest and fuel management practices and supportive of or neutral towards the Forsythe II project. The majority of respondents were also not likely to be engaged in or aware of the planned activities. The fact that the data suggest the majority of the respondents were broadly supportive of forest and fuel management, and that they reported they were relatively disengaged with the issue, suggests that most residents in the area accepted the USFS and its role managing adjacent public lands.

Author Contributions: Conceptualization, H.B.-S. and J.L.S.J.; Data curation, H.B.-S. and J.L.S.J.; Formal analysis, H.B.-S., E.A.V. and J.A.; Funding acquisition, J.L.S.J.; Methodology, H.B.-S.; Writing-original draft, H.B.-S. Writing-review \& editing, H.B.-S., J.L.S.J. and E.A.V. All authors have read and agreed to the published version of the manuscript.

Funding: This research was partially funded by The United States Department of Interior, Joint Fire Science Program, project 16-3-01-37.

Acknowledgments: We thank the residents of the Forsythe II area for responding to the survey administered in this study and the anonymous reviewers selected by the journal for their feedback. Publication of this article was funded by the University of Colorado Boulder Libraries Open Access Fund.

Conflicts of Interest: The authors declare no conflict of interest.

\section{References}

1. Stein, S.M.; Menakis, J.; Carr, M.A.; Comas, S.J.; Steward, S.I.; Cleveland, H.; Bramwell, L.; Radeloff, V.C. Wildfire, Wildlands, and People: Understanding and Preparing for Wildfire in the Wildland-Urban Interface; Gen. Tech. Rep. RMRS-GTR-299; Department of Agricuture, Forest Service, Rocky Mountain Research Station: Fort Collins, CO, USA, 2013; pp. 1-36.

2. Paveglio, T.; Carroll, M.S.; Absher, J.D.; Norton, T. Just blowing smoke? Residents' social construction of communication about wildfire. Environ. Commun. J. Nat. Culture 2009, 3, 76-94. [CrossRef]

3. Rieman, B.E.; Hessburg, P.F.; Luce, C.; Dare, M.R. Wildfire and management of forests and native fishes: Conflict or opportunity for convergent solutions? BioScience 2010, 60, 460-468. [CrossRef]

4. McCaffrey, S.; Toman, E.; Stidham, M.; Shindler, B. Social science research related to wildfire management: An overview of recent findings and future research needs. Int. J. Wildland Fire 2013, 22, 15-24. [CrossRef]

5. Shindler, B.A.; Toman, E.; McCaffrey, S.M. Public perspectives of fire, fuels and the Forest Service in the Great Lakes Region: A survey of citizen-agency communication and trust. Int. J. Wildland Fire 2009, 18, 157-164. [CrossRef]

6. McCaffrey, S. Understanding public perspectives of wildfire risk. In Wildfire Risk: Human Perceptions and Management Implications; Martin, W.E., Raish, C., Kent, B., Eds.; Resources for the Future: Washington, DC, USA, 2008; pp. 11-22.

7. Vaske, J.J.; Absher, J.D.; Bright, A.D. Salient value similarity, social trust and attitudes toward wildland fire management strategies. Hum. Ecol. Rev. 2007, 14, 223-232.

8. Calkin, D.E.; Cohen, J.D.; Finney, M.A.; Thompson, M.P. How risk management can prevent future wildfire disasters in the wildland-urban interface. Proc. Natl. Acad. Sci. USA 2014, 111, 746-747. [CrossRef]

9. Meldrum, J.R.; Champ, P.A.; Brenkert-Smith, H.; Warziniack, T.; Barth, C.M.; Falk, L.C. Understanding gaps between the risk perceptions of wildland-urban interface (WUI) residents and wildfire professionals. Risk Anal. 2015, 35, 1746-1761. [CrossRef] 
10. Remenick, L. The Role of Communication in Preparation for Wildland Fire: A Literature Review. Environ. Commun. 2018, 12, 164-176. [CrossRef]

11. Gibbons, P.; Van Bommel, L.; Gill, A.M.; Cary, G.J.; Driscoll, D.A.; Bradstock, R.A.; Knight, E.; Moritz, M.A.; Stephens, S.L.; Lindenmayer, D.B. Land management practices associated with house loss in wildfires. PLoS ONE 2012, 7, e29212. [CrossRef]

12. Syphard, A.D.; Brennan, T.J.; Keeley, J.E. The role of defensible space for residential structure protection during wildfires. Int. J. Wildland Fire 2014, 23, 1165-1175. [CrossRef]

13. Cohen, J.D. Preventing disaster: Home ignitability in the wildland-urban interface. J. For. 2000, 3, $15-21$.

14. Quarles, S.L.; Valachovic, Y.; Nakamura, G.M.; Nader, G.A.; De Lasaux, M.J. Home Survival in Wildfire-Prone Areas: Building Materials and Design Considerations. ANR 8393. 2010, pp. 1-22. Available online: https://escholarship.org/uc/item/4vt8w5qk (accessed on 23 December 2019).

15. Syphard, A.D.; Keeley, J.E.; Massada, A.B.; Brennan, T.J.; Radeloff, V.C. Housing arrangement and location determine the likelihood of housing loss due to wildfire. PLOS ONE 2012, 7, e33954. [CrossRef]

16. Gorte, R. The Rising Cost of Wildfire Protection; Headwaters Economics: Bozeman, MT, USA, 2013; Available online: https://headwaterseconomics.org/wp-content/uploads/fire-costs-background-report.pdf (accessed on 23 December 2019).

17. Radeloff, V.C.; Helmers, D.P.; Kramer, H.A.; Mockrin, M.H.; Alexandre, P.M.; Bar-Massada, A.; Butsic, V.; Hawbaker, T.J.; Martinuzzi, S.; Syphard, A.D.; et al. Rapid growth of the US wildland-urban interface raises wildfire risk. Proc. Natl. Acad. Sci. USA 2018, 115, 3314-3319. [CrossRef]

18. Jahn, J.L.S.; White, M.; Brenkert-Smith, H. My place or yours? Using spatial frames to understand the role of place in forest management conflicts. Soc. Nat. Resourc.. Forthcoming.

19. Jahn, J.L.S.; Brenkert-Smith, H. Defining "Resilient Landscapes" from Multiple Stakeholders in a Wildland-Urban Interface (WUI) Area. Final Project Report (16-3-01-37); 2019; p. 44 . Available online: https://www.firescience.gov/projects/16-3-01-37/project/16-3-01-37_final_report.pdf (accessed on 23 December 2019).

20. Dombeck, M.P. Thinking like a mountain: BLM's approach to ecosystem management. Ecol. Appl. 1996, 6, 699-702. [CrossRef]

21. Cortner, H.J.; Moote, M.A. The Politics of Ecosystem Management; Island Press: Washington, DC, USA, 1999.

22. Brunson MW, Shindler BA. Geographic variation in social acceptability of wildland fuels management in the western United States. Soc. Nat. Resour. 2004, 17, 661-678. [CrossRef]

23. Shindler, B.; Toman, E. Fuel reduction strategies in forest communities: A longitudinal analysis of public support. J. For. 2003, 101, 8-15.

24. Winter, G.; Vogt, C.A.; McCaffrey, S. Examining social trust in fuels management strategies. J. For. 2004, 102, 8-15.

25. McCaffrey, S.M. The Public and Wildland Fire Management: Social Science Findings for Manage; Gen. Tech. Rep. NRS-1; U.S. Department of Agriculture, Forest Service, Northern Research Station: Newtown Square, PA, USA, 2006; pp. 1-202.

26. Winter, G.J.; Vogt, C.; Fried, J.S. Fuel treatments at the wildland-urban interface: Common concerns in diverse regions. J. For. 2002, 100, 15-21.

27. Brunson, M.W.; Evans, J. Badly burned? Effects of an escaped prescribed burn on social acceptability of wildland fuels treatments. J. For. 2005, 103, 134-138.

28. Manzo, L.C. Beyond house and have: Toward a revisioning of emotional relationships with places. J. Environ. Psychol. 2003, 23, 47-61. [CrossRef]

29. Gieryn, T.F. A space for place in sociology. Annu. Rev. Sociol. 2000, 26, 463-496. [CrossRef]

30. Greider, T.; Garkovich, L. Landscapes: The social construction of nature and the environment. Rural Sociol. 1994, 59, 1-24. [CrossRef]

31. Buechler, S.M. Social Movements in Advanced Capitalism; Oxford University Press: New York, NY, USA, 2000; p. 256.

32. Goffman, E. Frame Analysis: An Essay on the Organization of Experience; Harvard University Press: Cambridge, MA, USA, 1974; p. 586.

33. Vaughan, E.; Seifert, M. Variability in the framing of risk issues. J. Oc. Issues 1992, 48, 119-135. [CrossRef]

34. Davis, C.B.; Lewicki, R.J. Environmental conflict resolution: Framing and intractability-An introduction. Environ. Pract. 2003, 5, 200-206. [CrossRef] 
35. Weick, K.E. Sensemaking in Organizations; SAGE Publications: Thousand Oaks, CA, USA, 1995; p. 321.

36. Bonaiuto, M.; Carrus, G.; Martorella, H.; Bonnes, M. Local identity processes and environmental attitudes in land use changes: The case of natural protected area. J. Econ. Psychol. 2002, 23, 631-653. [CrossRef]

37. Pellow, D. Spaces that teach. In Place Attachment; Springer: Boston, MA, USA, 1992; pp. 187-210.

38. White, D.D.; Virden, R.J.; van Riper, C.J. Effects of place identity, place dependence, and experience-use history on perceptions of recreation impacts in a natural setting. Environ. Manag. 2008, 42, 647-657. [CrossRef] [PubMed]

39. Paton, D.; Buergelt, P.T. Community engagement and wildfire preparedness: The influence of community diversity. Wildfire Community Facil. Prep. Resil. 2012, 2012, 241-259.

40. Paveglio, T.B.; Jakes, P.J.; Carrol, M.S.; Williams, D.R. Understanding social complexity within the wildland-urban interface: A new species of human habitation? Environ. Manag. 2009, 43, 1085-1095. [CrossRef]

41. Flint, C.G.; Haynes, R. Managing forest disturbances and community responses: Lessons from the Kenai Peninsula, Alaska. J. For. 2006, 104, 269-275.

42. Environmental Assessment. Forsythe II Project. Boulder Ranger District, Roosevelt National Forest. Boulder and Gilpin County, Colorado, 2016. Available online: https://www.fs.usda.gov/Internet/FSE_DOCUMENTS/ fseprd549691.pdf (accessed on 23 December 2019).

43. Forsythe II Decision. U.S. Forest Service. 2017. Available online: https://fs.usda.gov/Internet/FSE_ DOCUMENTS/fseprd549686.pdf (accessed on 23 December 2019).

44. Forsythe II Project Public Involvement. Boulder Ranger District, Roosevelt National Forest. Boulder and Gilpin County, Colorado. Available online: https://www.fs.usda.gov/detail/arp/landmanagement/ resourcemanagement/?cid=stelprd3853349 (accessed on 23 December 2019).

45. Forsythe II Project: Changes from Initial Proposal to Project Decision. Boulder Ranger District, Roosevelt National Forest. Boulder and Gilpin County, Colorado, 2017. Available online: https:/www.fs.usda.gov/ Internet/FSE_DOCUMENTS/fseprd549689.pdf (accessed on 23 December 2019).

46. Forsythe II Project: Changes from Draft Decision to Final Decision. Boulder Ranger District, Roosevelt National Forest. Boulder and Gilpin County, Colorado, 2017. Available online: https://www.fs.usda.gov/ Internet/FSE_DOCUMENTS/fseprd549690.pdf (accessed on 23 December 2019).

47. Toman, T.; Brenkert-Smith, H.; Curtis, A.; Rogers, M.; Stidham, M. Final Report 12-2-01-59: Managing Multi-Functional Landscapes at the Interface of Public Forests and Private Land: Advancing Understanding through a Comparison of Experience in U.S. and Australia. Final Report to the Joint Fire Science Program. 2015, pp. 1-15. Available online: https://researchoutput.csu.edu.au/ws/portalfiles/portal/21103030/1000006261_ published_report.pdf (accessed on 23 December 2019).

48. Weick, K.E. Sensemaking as an organizational dimension of global change. Organ. Dimens. Glob. Chang. 1999, 1999, 39-56.

49. Tracy, S.J. Qualitative Research Methods: Collecting Evidence, Crafting Analysis, Communicating Impact; John Wiley \& Sons: Malden, MA, USA, 2013; p. 368.

50. Creswell, J.W.; Plano Clark, V.L. Designing and Conducting Mixed Methods Research; Sage: Thousand Oaks, CA, USA, 2017; p. 520.

51. ZIP Code 80466. U.S. Census Bureau. Available online: https://www.unitedstateszipcodes.org/80466/ (accessed on 23 December 2019).

52. R Core Team. A Language and Environment for Statistical Computing; R Foundation for Statistical Computing: Vienna, Austria, 2018.

53. Shmueli, D.; Elliott, M.; Kaufman, S. Frame changes and the management of intractable conflicts. Confl. Resolut. Q. 2006, 24, 207-218. [CrossRef]

(C) 2019 by the authors. Licensee MDPI, Basel, Switzerland. This article is an open access article distributed under the terms and conditions of the Creative Commons Attribution (CC BY) license (http://creativecommons.org/licenses/by/4.0/). 